\title{
DFT: B3LYP/ LANL2DZ Study for the Removal of Fe, Ni, Cu, As, Cdl and Pb with Chitosan
}

\author{
Hend Ezzat ${ }^{1}$, A. A. Menazea ${ }^{2,3}$, Wessam Omara ${ }^{4,5}$, Osama H. Basyouni ${ }^{5,6}$, Samah A. Helmy ${ }^{7}$, Aya A. \\ Mohamed ${ }^{8}$, Walid Tawfik ${ }^{9}$, Medhat Ibrahim ${ }^{3, *}$ (D) \\ 1 Nano Technology Unit, Solar and Space Research Department, National Research Institute of Astronomy and Geophysics \\ (Nano NRIAG), 11731 Helwan, Cairo, Egypt \\ 2 Laser Technology Unit, National Research Centre, 12622 Dokki, Giza, Egypt \\ Spectroscopy Department, National Research Centre, 12622 Dokki, Giza, Egypt \\ 4 Materials Science Department- Institute of Graduate Studies and Research, Alexandria University, Alexandria, Egypt \\ 5 Egypt Nanotechnology Center, Cairo University, El-Sheikh Zayed, $6^{\text {th }}$ October, Giza 12588, Egypt \\ 6 Department of Physics, Faculty of Science, Kafrelsheikh University, Kafrelsheikh 33516, Egypt \\ 7 Physics Department, Special Physics Branch, Faculty of Science, Ain Shams University, 11566 Cairo, Egypt \\ Physics Department, Faculty of Science, Cairo University, Cairo, Egypt \\ $9 \quad$ National Institute of Laser NILES, Cairo University, Cairo, Egypt \\ * Correspondence: medahmed6@yahoo.com;
}

Scopus Author ID 8641587100

Received: 7.04.2020; Revised: 26.05.2020; Accepted: 27.05.2020; Published: 1.06.2020

\begin{abstract}
Human activities are responsible for the existence of heavy metals in the environment. The accumulation of these metals in the environment causes several risks, such as toxicological, mutagenic, and carcinogenic effects. Chitosan (Cs) based materials have been explored its competitive efficacy in heavy metals removal from contaminated water. In this study, an attempt is presented to develop a natural, reliable, and cost-effective biopolymer structure of Cs with a high ability to entrap some heavy metals, which can be found in polluted water. The correlation between Cs-heavy metals and its stability was studied by density functional theory (DFT) using B3LYP together with the basis set LANL2DZ. The observed results revealed that the bandgap energy values for Cs, Cs- $\mathrm{Fe}, \mathrm{Cs}-\mathrm{Ni}$, Cs-Cu, Cs-As, Cs$\mathrm{Cd}$ and $\mathrm{Cs}-\mathrm{Pb}$ were 2.571, 0.6147, 0.7176, 0.3396, 0.6648, 1.5007 and $0.4128 \mathrm{eV}$, respectively. The later showed that $\mathrm{Cs}$ structure has high selectivity and binding affinity to $\mathrm{Cu}$ and $\mathrm{Pb}$ hydrated metals, respectively rather than $\mathrm{Fe}, \mathrm{Ni}$, $\mathrm{As}$ and $\mathrm{Cd}$. The examined correlation between $\mathrm{Cu}$ and $\mathrm{Pb}$ with $\mathrm{Cs}$ revealed that $\mathrm{Cs}$ could be applied for sensing and removing of $\mathrm{Cu}$ and $\mathrm{Pb}$ from wastewater.
\end{abstract}

Keywords: Chitosan; DFT; LANL2DZ; heavy metals; wastewater.

(C) 2020 by the authors. This article is an open-access article distributed under the terms and conditions of the Creative Commons Attribution (CC BY) license (https://creativecommons.org/licenses/by/4.0/).

\section{Introduction}

Heavy metal pollution has occurred worldwide due to industrialization, mining, and manufacturing. Heavy metals removal from wastewater attracted high interest for all environmental agencies and communities all over the world [1]. The removal of these heavy metals from drinkable water takes a high priority because of its toxicity due to the formation of complexes inside the body cells; these complexes are not biodegradable [2,3]. In industrial wastewater, many toxic metals are often detected from the metal coating, battery industries, printing, painting and pigment industries, etc. [4, 5].

Cadmium $\mathrm{Cd}$, Lead $\mathrm{Pb}$, and Nickel $\mathrm{Ni}$ are among the most dangerous heavy metal pollutants generated from the electroplating industry, batteries, phosphate fertilizers, pigments, stabilizers, and alloys into the aquatic environment. They have possessed several risks to 
human health, causing hypertension, insomnia, pain, dizziness, anemia, irritability, muscle weakness, hallucinations, and renal damage hepatic damage, dysfunction of central nervous systems, cancer, and mutation [6-8].

Several techniques have been commonly used to remove toxic metals from wastewater, such as exchange of ions, chemical precipitation, complexation, extraction of liquid-liquid, reverse osmosis, the process of oxidation-reduction, evaporation, separation, adsorption, and Pulsed Laser Deposition [9-14]. However, these approaches are costly and ineffective, particularly when heavy metal ions are involved in wastewater at low concentrations. Adsorption is one of the most economical, practical, and widely used methods for the removal of toxic metals from the aqueous environment $[15,16]$.

Cs is an amino polysaccharide produced from chitin that is found naturally in some fungi. It is regarded as one of the most important and easiest bio-polymers used in different applications, such as protein and metal adsorption, medication guidance and gene delivery, magnetic resonance imaging, tissue design, and enzyme immobilization, food preservation, medical uses, particularly in medicinal products for obesity and high cholesterol disease, expanding their uses as a chelating agent and substantial metal trapper and in water treatment [17].

Cs is the most versatile biopolymer for a broad range of applications due to its biocompatibility, biodegradability, and antibacterial property. It demonstrates a successful biological action against pathogenic grams that is unusual in a linear biocompatible and biodegradable polysaccharide natural polymer extracted through the chitin deacetylating process, normally found in the hard external skeleton of shellfish, mollusks, and insects. Cs with low molecular weight usually demonstrate higher water dissolvability and better antibacterial properties compared to high molecular weight; Cs 's chemical modifications are the right choices for advancing its properties to be implemented in a wide field [18].

In recent days, researchers are interested in using Cs because this material is regarded as an ideal adsorbent where a polymer film is capable of heavy metal adsorption from wastewater. The removal of heavy metals such as; $\mathrm{Cd}, \mathrm{Pb}$, and $\mathrm{Ni}$ by $\mathrm{Cs}$ is considered a clever, low-cost idea in our life without any complicated experiments and could be very easy in use [19]. Cs include reactive hydroxyl-OH (non-specific binding site) and amino $-\mathrm{NH}_{2}$ groups (specific binding site), which can attach heavy metals and serve as chelating and reaction sites. Pure Cs has the property of agglomerating and forming a gel in aqueous media so that most hydroxyl and amino groups are inaccessible for binding metals [20,21]. Researches have been found that $\mathrm{NH}_{2}$ groups are the main reactive groups for adsorption of metal ions. Based on this, $\mathrm{OH}$ groups may also involve in adsorption mechanism. A different mechanism, such as electrostatic attraction and chelation, may involve adsorption of metal ions onto these different fictional groups in which the $\mathrm{pH}$ is an important factor. The free lone pair electrons on nitrogen may bind metal cations at $\mathrm{pH}$ close to neutrality (or weak acidity). At the same time, the protonation of amine groups in acidic solutions makes polymer behave in a cationic manner and, consequently, the potential for attracting metal anions. The chelation of metal cations by ligands in solution may result in the formation of metal anions, which therefore convert the chelation mechanism on $\mathrm{Cs}$ to an electrostatic attraction mechanism on protonated amine groups of the polymer [21,22].

The mechanism of selective adsorption was well explained by incorporating ionic scale effect and DFT analysis. Limited information is available on the microscopic complexation process between heavy metals and polar adsorbents, but theoretical calculations using quantum 
mechanical approaches have been used with great success. The DFT is a robust and efficient electronic structure method for describing metal systems. Recent studies have combined DFT techniques with experimental methodologies to describe the adsorption process and the interaction between heavy metals, including [Cd (II), Ni (II), Pb (II)], and Cs [23-25]. It is worth mentioning that DFT, as well as other molecular modeling tools, show potential applications for $\mathrm{Cs}$ as well as other members of biopolymers. Applications include understanding the electronic properties of biopolymers as well as their derivatives [26-32]. It is stated that understanding the electronic properties is an important step toward the functionalities of such emerging materials. They are investigating electronic properties of Cs as well as other biopolymers not only important for environmental applications but also in many other applications, whereas such classes of materials show the potential applications according to their unique properties [33-39].

In this work, the possible interaction between $\mathrm{Cs}$ and some heavy metals such as $\mathrm{Fe}$, $\mathrm{Ni}, \mathrm{Cu}, \mathrm{As}, \mathrm{Cd}$, and $\mathrm{Pb}$ is tried. This study is performed using molecular modeling DFT:B3LYP/LANL2DZ level of theory. The study including the geometrical stability and electronic properties of $\mathrm{Cs}$ with hydrated heavy metals.

\section{Materials and Methods}

Model molecules of $\mathrm{Cs}$ and $\mathrm{Cs}$ with hydrated metals as $\mathrm{Fe}, \mathrm{Ni}, \mathrm{Cu}, \mathrm{As}, \mathrm{Cd}$, and $\mathrm{Pb}$ were built. All the studied models were computed by the GAUSSIAN09 program [40] at Spectroscopy Department, National Research Centre, Egypt. Studied models were optimized with DFT theory at the B3LYP [41-43] level, together with the LANL2DZ basis set. Total dipole moment (TDM) and HOMO-LUMO bandgap energy, the contour of molecular electrostatic potential (MESP), were also calculated at the same level of theory.

\section{Results and Discussion}

\subsection{Model Structure.}

Model structures were built for simulating the possibility of using Cs as heavy metals removal. Models presented as three units of Cs representing the main model molecule. For simulating heavy metals in the aquatic environment, each of the studied heavy metals was correlated weakly with 6 water molecules $\left(\mathrm{H}_{2} \mathrm{O}\right)$ as $\mathrm{M}-6 \mathrm{H}_{2} \mathrm{O}$ where $\mathrm{M}$ is $\mathrm{Fe}, \mathrm{Ni}, \mathrm{Cu}, \mathrm{As}, \mathrm{Cd}$ and $\mathrm{Pb}$ respectively. The correlation between $\mathrm{Cs}$ and each hydrated metal was represented as an adsorbed state. Figure 1 shows models for $\mathrm{Cs}$ and $\mathrm{Cs}$ with hydrated metals $\mathrm{Fe}, \mathrm{Ni}, \mathrm{Cu}, \mathrm{As}$, $\mathrm{Cd}$, and $\mathrm{Pb}$, respectively. If the metal is going to interact with $\mathrm{Cs}$ through one bond, this could be instead of one water molecule if the metal is going to interact through two bonds then it will be through two water molecules. All model structures were computed using DFT theory at the B3LYP level and LANL2DZ basis set. HOMO-LUMO band gab energy and MESP were calculated at the same level of theory for all structures. It is stated earlier that physical parameters such as TDM, HOMO-LUMO band gap energy, and MESP are good descriptors for the reactivity of a given compound [44-46]. 


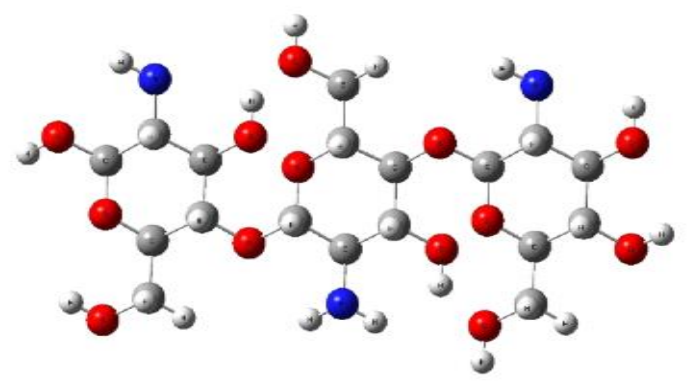

(a)

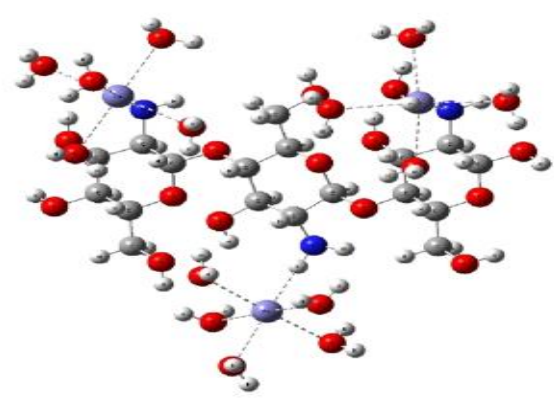

(b)

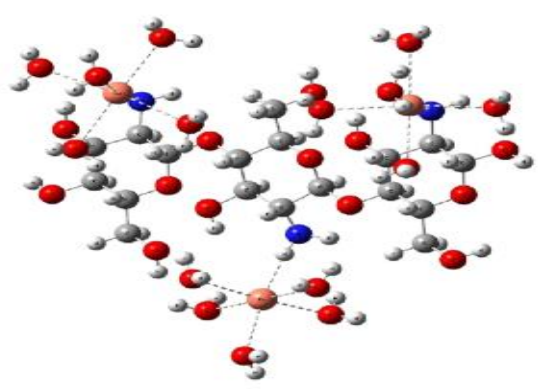

(d)

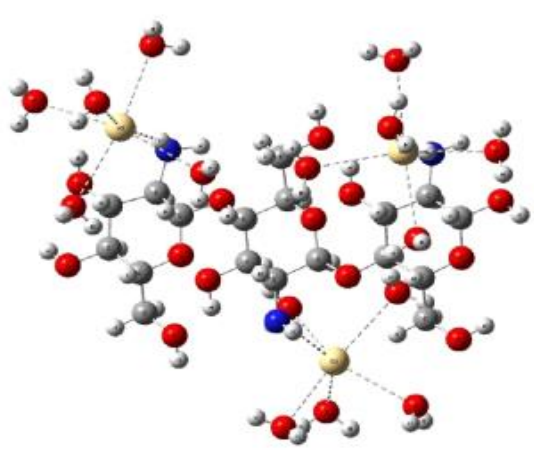

(I)

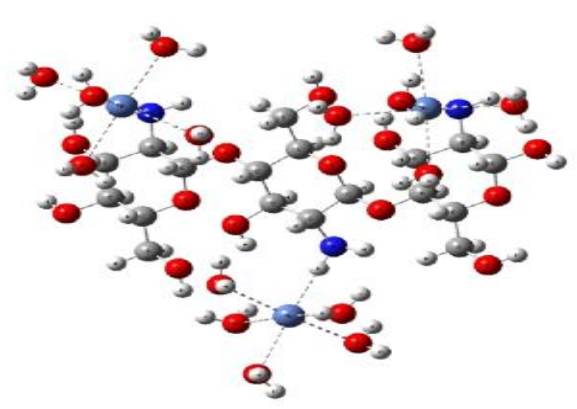

(c)

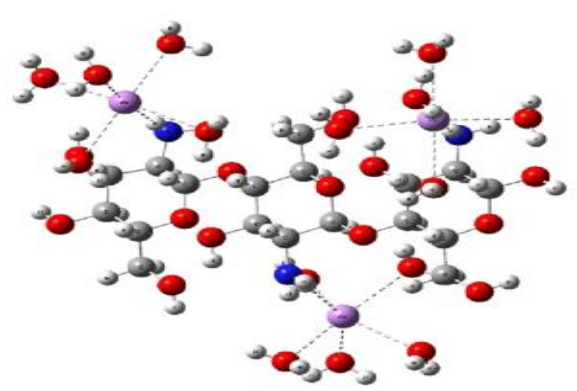

(e)

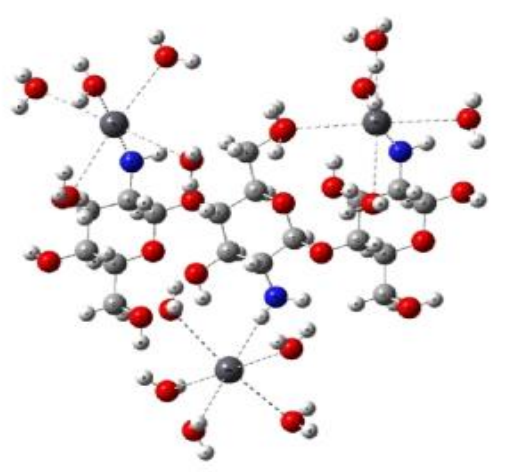

(g)

Figure 1. B3LYP/LANL2DZ calculaed optimized structure for (a) Chitosan; (b) Chitosan + Fe; (c) Chitosan + $\mathrm{Ni}$; (d) Chitosan $+\mathrm{Cu}$; (e) Chitosan + As; (f) Chitosan $+\mathrm{Cd}$; (g) Chitosan $+\mathrm{Pb}$.

\subsection{HOMO-LUMO calculations.}

HOMO-LUMO bandgap energy and TDM for proposed structures Cs and Cs with M$6 \mathrm{H}_{2} \mathrm{O}$ where $\mathrm{M}=\mathrm{Fe}, \mathrm{Ni}, \mathrm{Cu}, \mathrm{As}, \mathrm{Cd}$, and $\mathrm{Pb}$ were computed at the same level of theory. Figure 2 represents the calculated HOMO-LUMO band gap, which represents the distribution of orbitals around the molecule. For $\mathrm{Cs}$, the orbitals distributed uniformly around the three units. When Cs interacted with metals, orbital distribution was localized around metals. Conversions appeared in HOMO-LUMO bandgap energy and TDM listed in table 1. For Cs, three units 
model bandgap energy were $2.5712 \mathrm{eV}$ and TDM were 4.0939 Debye. However, Cs with M$6 \mathrm{H}_{2} \mathrm{O}$ where $\mathrm{M}=\mathrm{Fe}, \mathrm{Ni}, \mathrm{Cu}, \mathrm{As}, \mathrm{Cd}$, and $\mathrm{Pb}$ recorded changes in the two parameters. Accordingly, $\mathrm{Cs}+\mathrm{Fe}$ HOMO-LUMO bandgap decreased to $0.6147 \mathrm{eV}$, and TDM increased to 13.2259 Debye, which means that Cs affected by Fe. Also, Cs + Ni bandgap and TDM changed as $0.7176 \mathrm{eV}$ and 15.6366 Debye, respectively, which also means that $\mathrm{Ni}$ effect on Cs.

Furthermore, $\mathrm{Cs}+\mathrm{Cu}$ recorded a change in bandgap and TDM as $0.3396 \mathrm{eV}$ and 27.8830 Debye, respectively. Cs + As also bandgap and TDM changed to $0.6648 \mathrm{eV}$ and 19.0923 Debye. Similarly, Cs + Cd changed to $1.5007 \mathrm{eV}$ and 17.3977 Debye. Equally, for $\mathrm{Cs}+\mathrm{Pb}$ bandgap and TDM were $0.4128 \mathrm{eV}$ and 17.6536 Debye. When the TDM increased while the bandgap energy decreased, this means that the interaction occurrence ability is high. From all data, Cs could interact with all studied metals but have more ability to interact with $\mathrm{Cu}$ and $\mathrm{Pb}$ that they have the highest TDM value and the lowest band gap value.

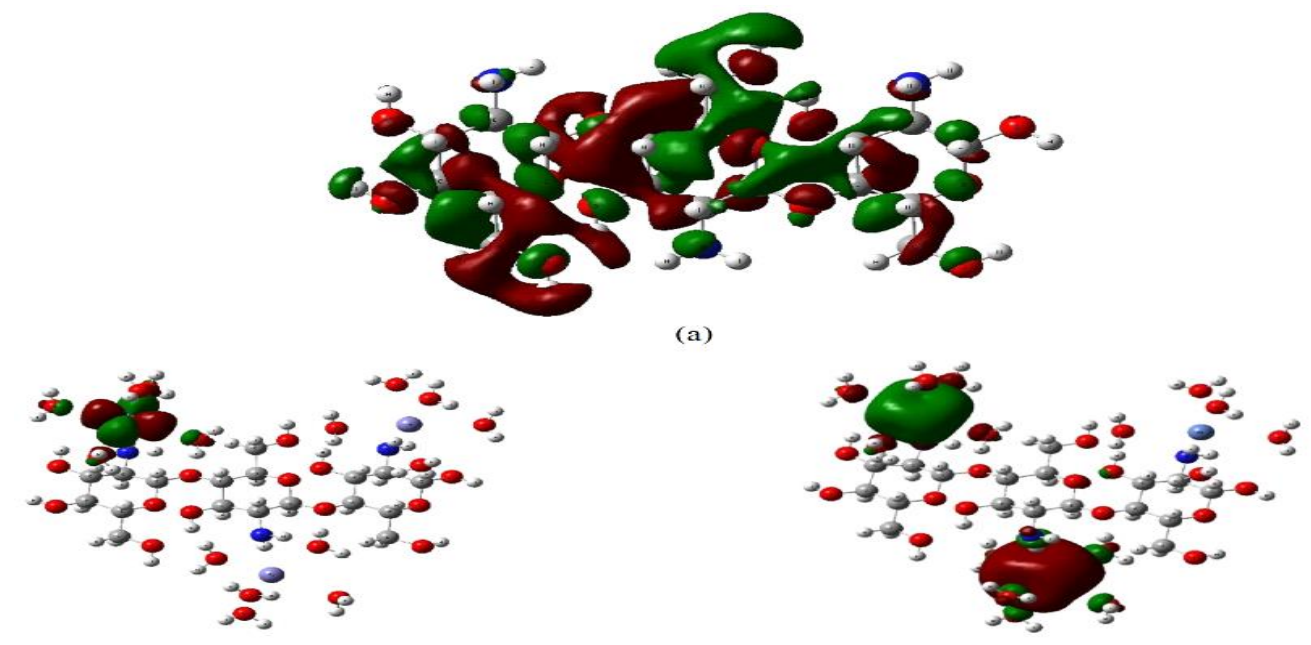

(b)

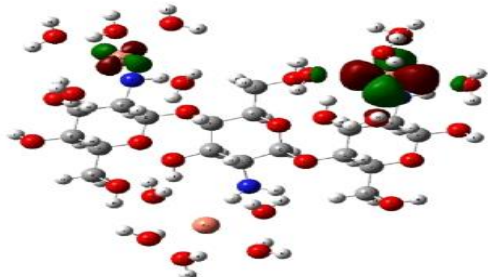

(d)

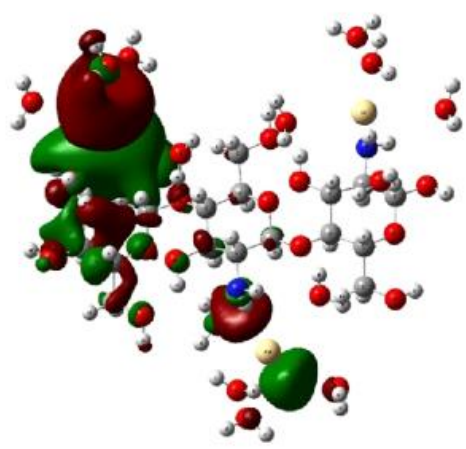

(f)

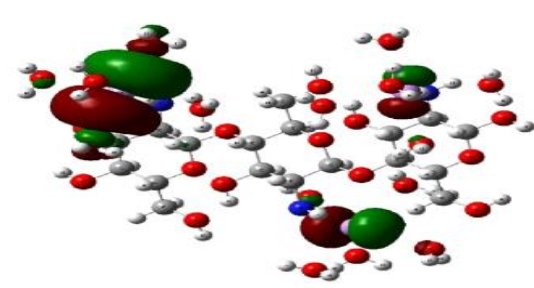

(c)

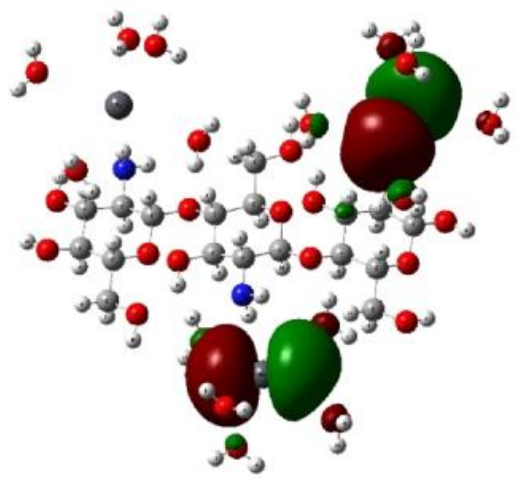

(g)

Figure 2. Calculated B3LYP/LANL2DZ HOMO-LUMO band gap energy for (a) Chitosan; (b) Chitosan + Fe;

(c) Chitosan + Ni; (d) Chitosan + Cu; (e) Chitosan + As; (f) Chitosan + Cd; (g) Chitosan $+\mathrm{Pb}$. 
Table 1. Calculated TDM (Debye) and HOMO-LUMO bandgap energy $\Delta \mathrm{E}(\mathrm{eV})$ using B3LYP/LANL2DZ for

Chitosan, Chitosan $+\mathrm{Fe}$, Chitosan $+\mathrm{Ni}$, Chitosan $+\mathrm{Cu}$, Chitosan $+\mathrm{As}$, Chitosan $+\mathrm{Cd}$ and, Chitosan $+\mathrm{Pb}$

\begin{tabular}{l|l|l} 
Structure & TDM & $\Delta \mathrm{E}$ \\
\hline Chitosan & 4.0939 & 2.5712 \\
\hline Chitosan $+\mathrm{Fe}$ & 13.2259 & 0.6147 \\
\hline Chitosan + Ni & 15.6366 & 0.7176 \\
\hline Chitosan + Cu & 27.8830 & 0.3396 \\
\hline Chitosan + As & 19.0923 & 0.6648 \\
\hline Chitosan + Cd & 17.3977 & 1.5007 \\
\hline Chitosan + Pb & 17.6536 & 0.4128
\end{tabular}

\subsection{Molecular electrostatic potential.}

MESP characterizes the number of neighboring charges, nuclei, and electrons' strength at a certain location. The interpretation of MESP clarified according to the color extended gradually as red, orange, yellow, green, and blue, respectively. Ranged color represents the MESP intensities variation, where red color signified the lowest MESP value, and the blue color signified the highest MESP value. The importance of MESP calculation is knowing the molecule active site and its interaction ability with neighboring.

Figure 3a represents MESP for $\mathrm{Cs}$, a low potential red region signifies electrons abundance. Accordingly, the active sites of $\mathrm{Cs}$ are the $\mathrm{NH}_{2}$ active groups. Figures $3 \mathrm{~b}, \mathrm{c}, \mathrm{d}$, e, $\mathrm{f}$, and $\mathrm{g}$ illustrate the contour MESP for the adsorption of hydrated metals $\mathrm{Fe}, \mathrm{Ni}, \mathrm{Cu}, \mathrm{As}, \mathrm{Cd}$, and $\mathrm{Pb}$. MESP contour specified that the structures be more reactive according to the interaction where the red region localized. The present computational work proves that molecular modeling at DFT level is providing valuable data for the removal of heavy metals from the environment using biopolymers, which is in good agreement with previous findings [47-50].

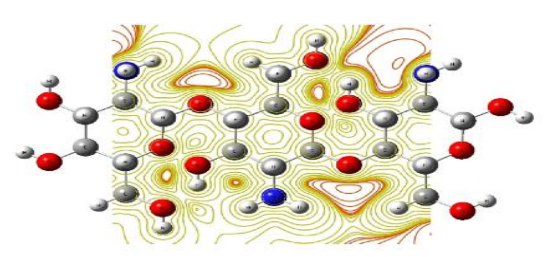

(a)

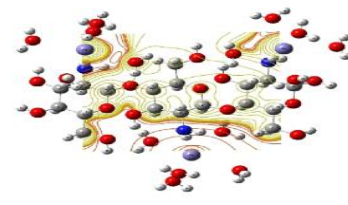

(b)

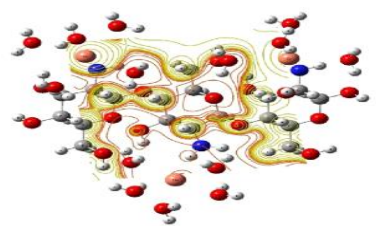

(d)

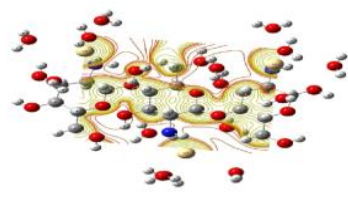

(ก)

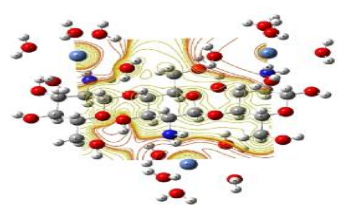

(c)

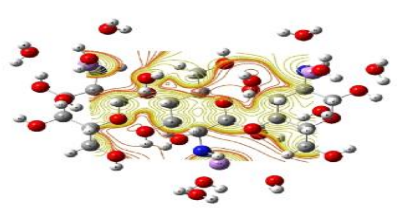

(e)

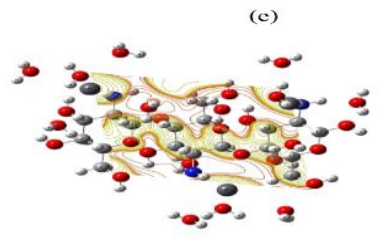

(g)

Figure 3. Calculated B3LYP/LANL2DZ MESP for (a) Chitosan; (b) Chitosan + Fe; (c) Chitosan + Ni; (d) Chitosan $+\mathrm{Cu}$; (e) Chitosan + As; (f) Chitosan $+\mathrm{Cd}$; (g) Chitosan $+\mathrm{Pb}$. 


\section{Conclusions}

DFT: B3LYP/LANL2DZ model was used to study the ability of Cs to interact with heavy metals in hydrated form. This interaction is an important step for applying a green method for the remediation of heavy metals from the aquatic environment. Results showed that $\mathrm{Cs}$ can interact with all studied hydrated metals but has more ability to interact with $\mathrm{Cu}$ and $\mathrm{Pb}$ that they have the highest TDM and the lowest bandgap energy. Cs structure has high selectivity and binding affinity to $\mathrm{Cu}$ and $\mathrm{Pb}$ hydrated metals, respectively, rather than $\mathrm{Fe}, \mathrm{Ni}$, $\mathrm{As}$, and $\mathrm{Cd}$. The examined correlation between $\mathrm{Cu}$ and $\mathrm{Pb}$ with $\mathrm{Cs}$ revealed that $\mathrm{Cs}$ could be applied for sensing and removal of $\mathrm{Cu}$ and $\mathrm{Pb}$ from wastewater. This computational study dedicated $\mathrm{Cs}$ in nanoscale as a green selective tool for the remediation of heavy metal from the aquatic environment.

\section{Funding}

This research received no external funding.

\section{Acknowledgments}

\section{This research has no acknowledgment.}

\section{Conflicts of Interest}

The authors declare no conflict of interest.

\section{References}

1. Abdullah, N.; Yusof, N.; Lau, W.J.; Jaafar, J.; Ismail, A.F. Recent trends of heavy metal removal from water/wastewater by membrane technologies. Journal of Industrial and Engineering Chemistry 2019, 76, 1738, https://doi.org/10.1016/j.jiec.2019.03.029.

2. Zhao, G.; Huang, X.; Tang, Z.; Huang, Q.; Niu, F.; Wang, X.. Polymer-based nanocomposites for heavy metal ions removal from aqueous solution: a review. Polymer Chemistry 2018, 9, 3562-3582, https://doi.org/10.1039/C8PY00484F

3. Lv, B.; Xing, M.; Yang, J. Speciation and transformation of heavy metals during vermicomposting of animal manure. Bioresoure Technology 2016, 209, 397-401, https://doi.org/10.1016/j.biortech.2016.03.015.

4. Achary, M.S.; Satpathy, K.K.; Panigrahi, S.; Mohanty, A.K.; Padhi, R.K.; Biswas, S.; Prabhu, R.K.; Vijayalakshmi, S.; Panigrahy, R.C. Concentration of heavy metals in the food chain components of the nearshore coastal waters of Kalpakkam, southeast coast of India. Food Control 2017, 72, 232-243, https://doi.org/10.1016/j.foodcont.2016.04.028.

5. Ahmad, S.Z.N.; Salleh, W.N.W.; Ismail, A.F.; Yusof, N.; Yusop, M.Z.M.; Aziz, F. Adsorptive removal of heavy metal ions using graphene-based nanomaterials: Toxicity, roles of functional groups and mechanisms. Chemosphere 2020, 248, https://doi.org/10.1016/j.chemosphere.2020.126008.

6. Madala, S.; Nadavala, S.K.; Vudagandla, S.; Boddu, V.M.; Abburi, K.. Equilibrium, kinetics and thermodynamics of Cadmium (II) biosorption on to composite chitosan biosorbent. Arabian Journal of Chemistry 2017, 10, S1883-S1893, https://doi.org/10.1016/j.arabjc.2013.07.017.

7. Rahman, Z.; Singh, V.P. The relative impact of toxic heavy metals (THMs)(arsenic (As), cadmium (Cd), chromium $(\mathrm{Cr})(\mathrm{VI})$, mercury $(\mathrm{Hg})$, and lead $(\mathrm{Pb})$ ) on the total environment: an overview. Environmental Monitoring and Assessment 2019, 191, https://doi.org/10.1007/s10661-019-7528-7.

8. Saini, S.; Dhania, G. Cadmium as an Environmental Pollutant: Ecotoxicological Effects, Health Hazards, and Bioremediation Approaches for Its Detoxification from Contaminated Sites. In: Bioremediation of Industrial Waste for Environmental Safety Springer, Singapore 2020; pp. 357-387, https://doi.org/10.1007/978-981-131891-7.

9. Chen, Q.; Yao, Y.; Li, X.; Lu, J.; Zhou, J.; Huang, Z. Comparison of heavy metal removals from aqueous solutions by chemical precipitation and characteristics of precipitates. Journal of Water Process Engineering 2018, 26, 89-300, https://doi.org/10.1016/j.jwpe.2018.11.003 
10. Li, Y.; Xu, Z.; Liu, S.; Zhang, J.; Yang, X. Molecular simulation of reverse osmosis for heavy metal ions using functionalized nanoporous graphenes. Computational Materials Science 2017, 139, 65-74, https://doi.org/10.1016/j.commatsci.2017.07.032.

11. Bin, H.; Yang, Y.; Cai, L.; Yang, L.; Roszak, S. Enhancing mercury removal across air pollution control devices for coal-fired power plants by desulfurization wastewater evaporation. Environmental Technology 2019, 40, 154-162, https://doi.org/10.1080/09593330.2017.1380716.

12. Fang, L.; Li, L.; Qu, Z.; Xu, H.; Xu, J.; Yan, N. A novel method for the sequential removal and separation of multiple heavy metals from wastewater. Journal of Hazardous Materials 2018, 342, 617-624, http://dx.doi.org/10.1016/j.jhazmat.2017.08.072.

13. Zakaria, M.A.; Menazea, A.A.; Mostafa, A.M.; Al-Ashkar, E.A. Ultra-thin silver nanoparticles film prepared via pulsed laser deposition: Synthesis, characterization, and its catalytic activity on reduction of 4nitrophenol. Surfaces and Interfaces 2020, 19, https://doi.org/10.1016/j.surfin.2020.100438.

14. Naushad, M.; Sharma, G.; Kumar, A.; Sharma, S.; Ghfar, A.A.; Bhatnagar, A.; Stadler, F.J.; Khan, M.R. Efficient removal of toxic phosphate anions from aqueous environment using pectin based quaternary amino anion exchanger. International Journal of Biological Macromolecules 2018, 106, 1-10, https://doi.org/10.1038/s41598-020-60021-6.

15. Yu, H.R.; Hu, J.Q.; Liu, Z.; Ju, X.J.; Xie, R.; Wang, W.; Chu, L.Y. Ion-recognizable hydrogels for efficient removal of cesium ions from aqueous environment. Journal of Hazardous Materials 2017, 323, 632-640, https://doi.org/10.1016/j.jhazmat.2016.10.024.

16. Menazea, A.A.; Mostafa, A.M.; Al-Ashkar, E.A. Impact of $\mathrm{CuO}$ doping on the properties of $\mathrm{CdO}$ thin films on the catalytic degradation by using pulsed-Laser deposition technique. Optical Materials 2020, 100, 109663, https://doi.org/10.1016/j.optmat.2020.109663.

17. Menazea, A.A.; Eid, M.M.; Ahmed, M.K. Synthesis, characterization, and evaluation of antimicrobial activity of novel Chitosan/Tigecycline composite. International Journal of Biological Macromolecules 2020, 147, 194-199, https://doi.org/10.1016/j.ijbiomac.2020.01.041.

18. Abdelghany, A.M.; Menazea, A.A.; Ismail, A.M. Synthesis, characterization and antimicrobial activity of Chitosan/Polyvinyl Alcohol blend doped with Hibiscus Sabdariffa L. extract. Journal of Molecular Structure 2019, 1197, 603-609, https://doi.org/10.1016/j.molstruc.2019.07.089.

19. Vunain, E.; Mishra, A.K.; Mamba, B.B. Dendrimers, mesoporous silicas and chitosan-based nanosorbents for the removal of heavy-metal ions: A review. International Journal of Biological Macromolecules 2016, 86, 570-586, https://doi.org/10.1016/j.ijbiomac.2016.02.005.

20. Abdullah, N.H.; Shameli, K.; Abdullah, E.C.; Abdullah, L.C. Solid matrices for fabrication of magnetic iron oxide nanocomposites: Synthesis, properties, and application for the adsorption of heavy metal ions and dyes. Composites Part B: Engineering 2019, 162, 538-568, https://doi.org/10.1016/j.compositesb.2018.12.075.

21. Sutirman, Z.A.; Sanagi, M.M.; Abd Karim, K.J.; Wan Ibrahim, W.A.; Naim, A. Chitosan-based Adsorbents for the Removal of Metal Ions from Aqueous Solutions. Malaysian Journal of Analytical Sciences 2018, 22, 839-850, https://doi.org/10.17576/mjas-2018-2205-11.

22. Zhang, Y.; Xue, Q.; Li, F.; Dai, J. Removal of heavy metal ions from wastewater by capacitive deionization using polypyrrole/chitosan composite electrode. Adsorption Science \& Technology 2019, 37, 205-216, https://doi.org/10.1177/0263617418822225.

23. Vakili, M.; Deng, S.; Cagnetta, G.; Wang, W.; Meng, P.; Liu, D.; Yu, G. Regeneration of chitosan-based adsorbents used in heavy metal adsorption: A review. Separation and Purification Technology 2019, 224, 373-387, https://doi.org/10.1016/j.seppur.2019.05.040.

24. Wang, B.; Bai, Z.; Jiang, H.; Prinsen, P.; Luque, R.; Zhao, S.; Xuan, J. Selective heavy metal removal and water purification by microfluidically-generated chitosan microspheres: Characteristics, modeling and application. Journal of Hazardous Materials $2019, \quad 364, \quad$ 192-205, https://doi.org/10.1016/j.jhazmat.2018.10.024.

25. Vieira, C.L.; Sanches Neto, F.O.; Carvalho-Silva, V.H.; Signini, R. Design of apolar chitosan-type adsorbent for removal of $\mathrm{Cu}(\mathrm{II})$ and $\mathrm{Pb}(\mathrm{II})$ : An experimental and DFT viewpoint of the complexation process. Journal of Environmental Chemical Engineering 2019, 7, https://doi.org/10.1016/j.jece.2019.103070.

26. Bayoumy, A.M.; El-Sayed, E.M.; Omar, A.; Ibrahim, M. Emerging Applications of Chitosan: From Biology to Environment. Biointerface Research in Applied Chemistry 2018, 8, 3368-3380.

27. Grenni, P.; Barra Caracciolo, A.; Mariani, L.; Cardoni, M.; Riccucci, C.; Elhaes, H.; Ibrahim, M.A. Effectiveness of a new green technology for metal removal from contaminated water. Microchemical Journal 2019, 147, 1010-1020, https://doi.org/10.1016/j.microc.2019.04.026.

28. Fahmy, A.; Khafagy, R.M.; Elhaes, H.; Ibrahim, M. A. Molecular Properties of Polyvinyl Alcohol/Sodium Alginate Composite, Biointerface Research in Applied Chemistry 2020, 10, 4734-4739, https://doi.org/10.33263/BRIAC101.734739.

29. Ibrahim, A.; Elhaes, H.; Meng, F.; Ibrahim, M. Effect of Hydration on the Physical Properties of Glucose, Biointerface Research in Applied Chemistry 2019, 8, 4114-4118.

30. Salamatmanesh, A.; Heydari, A.; Nahzomi, H.T. Stabilizing Pd on magnetic phosphine-functionalized cellulose: DFT study and catalytic performance under deep eutectic solvent assisted conditions. Carbohydrate Polymers 2020, 235, https://doi.org/10.1016/j.carbpol.2020.115947. 
31. Asadi-Ojaee, S.S.; Mirabi, A.; Rad, A.S.; Movaghgharnezhad, S.; Hallajian, S. Removal of Bismuth (III) ions from water solution using a cellulose-based nanocomposite: A detailed study by DFT and experimental insights. Journal of Molecular Liquids 2019, 295, https://doi.org/10.1016/j.molliq.2019.111723.

32. Abdel-Bary, A.S.; Tolan, D.A.; Nassar, M.Y.; Taketsugu, T.; El-Nahas, A.M. Chitosan, magnetite, silicon dioxide, and graphene oxide nanocomposites: Synthesis, characterization, efficiency as cisplatin drug delivery, and DFT calculations. International Journal of Biological Macromolecules 2020, 154, 621-633, https://doi.org/10.1016/j.ijbiomac.2020.03.106.

33. Keshavarz, S.T.; Imani, M.; Farahmandghavi, F. Adsorption and solidification of peppermint oil on microcrystalline cellulose surface: An experimental and DFT study. Journal of Molecular Structure 2020, 1205, 127558, https://doi.org/10.1016/j.molstruc.2019.127558.

34. Hayakawa, D.; Gouda, H.; Hirono, S.; Ueda, K. DFT study of the influence of acetyl groups of cellulose acetate on its intrinsic birefringence and wavelength dependence. Carbohydrate Polymers 2019, 207, 122130, https://doi.org/10.1016/j.carbpol.2018.11.074.

35. Gao, X.; Li, M.; Zhao, Y.; Zhang, Y. Mechanistic study of selective adsorption of $\mathrm{Hg} 2+$ ion by porous alginate beads. Chemical Engineering Journal 2019, 378, https://doi.org/10.1016/j.cej.2019.122096.

36. Jmiai, A.; El Ibrahimi, B.; Tara, A.; Bazzi, I.; Oukhrib, R.; El Issami, S.; Jbara, O.; Bazzi, L.; Hilali, M. The effect of the two biopolymers "sodium alginate and chitosan" on the inhibition of copper corrosion in $1 \mathrm{M}$ hydrochloric acid. Materials Today: $\quad$ Proceedings $\quad \mathbf{2 0 2 0}, \quad 22, \quad 12-15$, https://doi.org/10.1016/j.matpr.2019.08.057.

37. Badry, R.; El-Khodary, S.; Elhaes, H.; Nada, N.; Ibrahim, M. On the Molecular Modeling Analyses of Sodium Carboxymethyl Cellulose Treated with Acetic Acid. Letters in Applied NanoBioScience 2019, 8, 553-557.

38. Bayoumy, A.M.; Youssif, G.; Elgohary, E.A.; Husien, S.; Salah El Deen, H.; Albeltagy, N.M.; Abdelnaby, D.M.; Medhat, A.; Elhaes, H.; Ibrahim, M.A. Impact of solvation on the geometrical parameters of some amino acids. Letters in Applied NanoBioScience 2019, 8, 567-570.

39. Kakati, M.; Das, D.; Das, P.; Sanjeev, A.; Mattaparthi, V.S.K. Effect of ethanol as molecular crowding agent on the conformational dynamics of asynuclein. Letters in Applied NanoBioScience 2020, 9, 779-783.

40. Frisch, M.J.; et.al. Revision B. 01, Gaussian. Inc., Wallingford CT 2010.

41. Becke, A.D. Density-functional thermochemistry. III. The role of exact exchange. The Journal of Chemical Physics 1993, 98, 5648-5652, https://doi.org/10.1063/1.464913.

42. Lee, C.; Yang, W.; Parr, R.G. Development of the Colle-Salvetti correlation-energy formula into a functional of the electron density. Physical Review B 1988, 37, 785-789, https://doi.org/10.1103/physrevb.37.785.

43. Miehlich, B.; Savin, A.; Stoll, H.; Preuss, H. Results obtained with the correlation energy density functionals of becke and Lee, Yang and Parr. Chemical Physics Letters 1989, 157, 200-206, https://doi.org/10.1016/0009-2614(89)87234-3.

44. Şahin, Z.S.; Şenöz, H.I.; Tezcan, H.; Büyükgüngör, O. Synthesis, spectral analysis, structural elucidation and quantum chemical studies of (E)-methyl-4-[(2-phenylhydrazono)methyl]benzoate. Spectrochimica Acta A 2015, 143, 91-100, https://doi.org/10.1016/j.saa.2015.02.032.

45. Politzer, P.; Murray, J.S. Molecular Electrostatic Potentials. In Concepts and Applications, (Theoretical and Computational Chemistry). 1st ed. Murray, J.S.; Sen, K. Eds. Elsevier: Amsterdam, Volume 3, The Netherlands, 1996; pp.649-660.

46. Ibrahim, M.; El-Haes, H. Computational Spectroscopic Study of Copper, Cadmium, Lead and Zinc Interactions in the Environment. International Journal of Environment and Pollution 2005, 23, 417-424, http://dx.doi.org/10.1504/IJEP.2005.007604.

47. Ibrahim, M.; Mahmoud, A.A. Computational Notes on the Reactivity of Some Functional Groups. Journal of Computational and Theoretical Nanoscience 2009, 6, 1523-1526, https://doi.org/10.1166/jctn.2009.1205.

48. Normaya, E.; Ahmad Hamdan, M.F.; Ahmad, M.N.; Aziz, Y.F.A.; Bulat, K.H.K. DFT/TD-DFT study on development and optimization of 1- anilino-3-phenyliminourea as a colorimetric chemosensor for $\mathrm{Hg} 2+$ recognition in aqueous medium. Journal of Molecular Structure 2020, 1206, https://doi.org/10.1016/j.molstruc.2020.127699.

49. Liu, X.; Han, Y.; Cheng, Y.; Xu, G. Microwave-assisted ammonia modification of activated carbon for effective removal of phenol from wastewater: DFT and experiment study. Applied Surface Science 2020, 518, https://doi.org/10.1016/j.apsusc.2020.146258.

50. El-Gammal, O.A.; Fouda, A.A.; Nabih, D.M. Synthesis, spectral characterization, DFT and in vitro antibacterial activity of $\mathrm{Zn}(\mathrm{II}), \mathrm{Cd}(\mathrm{II})$ and $\mathrm{Hg}$ (II) complexes derived from a new thiosemicarbazide. Letters in Applied NanoBioScience 2019, 8, 715-722, https://doi.org/10.33263/LIANBS84.715722. 